\title{
Estudo da Interação das Nanopartículas de Dióxido de Titânio em Solos de Aterro Controlado Contaminados por Óxido de Cobre.
}

\author{
Interation Study of Titanium Dioxide Nanoparticles in Copper Oxide \\ Contaminated Controlled Soils.
}

\author{
1 Jose Adilson de Castro \\ 1 Mayara Lisboa Santos \\ 1 Luiz Carlos Rolim Lopes \\ 2 Fabiano Alves de Oliveira \\ 3 Elizabeth Mendes de Oliveira beth.mendes.oliveira@gmail.com
}

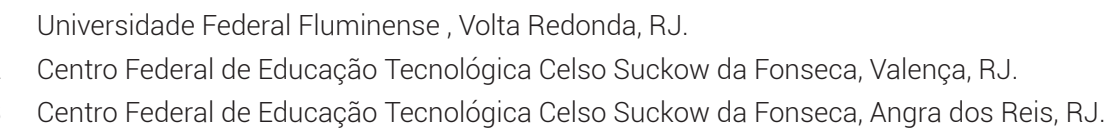

\section{Resumo:}

As nanopartículas representam, atualmente, uma nova e ampla classe de contaminantes produzidos pelo homem e são cada vez mais comuns nos ambientes naturais, visto que as atividades industriais envolvendo a nanotecnologia crescem de modo acelerado. Dessa forma, torna-se extremamente relevante compreender o transporte e o destino dos materiais nanoparticulados que são lançados no ambiente, para, então, identificar os fenômenos físicos e químicos que ocorrem provenientes da disposição de resíduos. 0 objetivo geral deste trabalho é criar informação científica necessária para melhor compreender o comportamento e o transporte de nanopartículas $\mathrm{TiO}_{2}$ em suspensões aquosas através de solos impregnados com cobre, permitindo, assim, que a produção e o uso de nanomateriais nocivos possam ser mais bem controlados, evitando os efeitos adversos à saúde humana e os custosos esforços para a remediação. Em particular, neste trabalho, foram escolhidos dióxido de titânio, por ser um nanomaterial largamente utilizado em escala industrial, e o óxido de cobre, por sua vez, por ser um contaminante de solo onipresente, o que torna singular a necessidade do estudo de seu transporte através do meio ambiente, especialmente em solos e águas. Para tal conhecimento, serão realizados ensaios experimentais, utilizando-se solo impregnado com óxido de cobre em suspensão aquosa de $\mathrm{TiO}_{2}$.

\section{Palavras-chave:}

Nanopartículas de $\mathrm{TiO}_{2}$ nanopartículas de $\mathrm{CuO}$; colunas de solo e nanosight.

\begin{abstract}
:
Nanoparticles today represent a new and wide class of man-made contaminants and are increasingly common in natural environments, as industrial activities involving nanotechnology grow rapidly. In this way, it becomes extremely relevant to understand the transport and destination of the nanoparticulate materials that are released in the environment to identify the physical and chemical phenomena that occur from the waste disposal. The general objective of this work is to create scientific information necessary to better understand the behavior and transport of TiO2 nanoparticles in aqueous suspensions through copper impregnated soils. Thus allowing the production and use of harmful nanomaterials to be better controlled, avoiding the adverse effects on human health and costly efforts for remediation. In particular, in this work titanium dioxide was chosen because it is a nanomaterial widely used in industrial scale and copper oxide in turn, being a ubiquitous soil contaminant. This makes the need to study transport through the environment, especially in soils and waters, unique. For this knowledge will be realized experimental tests of and using soil impregnated with copper in aqueous suspension of $\mathrm{TiO}_{2}$.
\end{abstract}

\section{Keywords:}

Nanoparticles of $\mathrm{TiO}_{2}$, Nanoparticles of CuO, Columns of Soil and Nanosight.

\section{Como você deve citar?}

OLIVEIRA, Elizabeth Mendes de. Estudo da interação das nanopartículas de dióxido de titânio em solos de aterro controlado contaminados por óxido de cobre. Cadernos UniFOA, Volta Redonda, n. 33, p. 17-24, abr. 2017. 
Estudo da Interação das Nanopartículas de Dióxido de Titânio em Solos de Aterro

Controlado Contaminados por Óxido de Cobre.

\section{INTRODUÇÃO}

Com o desenvolvimento da nanotecnologia, grandes quantidades de novos materiais estão sendo produzidos e liberados no meio ambiente. Desse modo, torna-se de suma importância compreender o destino e o transporte dos materiais nanoparticulados no ambiente, para, assim, poder identificar as possíveis rotas de exposição aos seres humanos e ao ecossistema, assim como os processos e fenômenos que ocorrem durante a contaminação de solos, em decorrência de disposição de resíduos de diferentes origens (HANDY et al., 2008).

Os benefícios dos NMs (nanomateriais) são potencialmente grandes, o que impulsionou a sua aplicação numa vasta gama de produtos e processos como: a nanoengenharia de partículas de titânio para painéis solares e tintas; o desenvolvimento de implantes e de superfícies para a engenharia de tecidos biológicos; a aplicação de nanotubos de carbono em pneus; a aplicação de nanofibras de carbono como protetores de tecidos; e, ainda, a inclusão de nanomateriais à base de óxido de titânio ou de proteínas em sabonetes, shampoo e detergentes (WIESNER et al., 2006; HEIDEN et al., 2008; HANDY et al., 2008; ZHANG et al., 2009; WANG et al., 2009).

No entanto, a emissão descontrolada de nanoparticulados no meio ambiente vem crescendo exponencialmente na última década, visto que o reconhecimento de que a produção, utilização, e eliminação desses NMs (nanomateriais) podem levar à sua dispersão no ambiente em concentrações capazes de induzirem efeitos na saúde humana e nos ecossistemas (WIESNER et al., 2006; KLAINE et al., 2008). Desse modo, o conhecimento da influência das nanopartículas ou de como elas podem modificar o ecossistema é extremamente relevante em uma área atualmente limitada, visto que os efeitos quânticos, geralmente negligenciados na escala macro, não poderão ser negligenciados (OLIVEIRA, 2015).

Nesta pesquisa, serão estudadas as nanopartículas de $\mathrm{TiO}_{2}$ presentes em solos de aterros controlados. A escolha do dióxido de titânio se deve ao fato de que é um dos nanomateriais mais utilizados em escala industrial. Dando sequência, foram analisadas as interações do $\mathrm{TiO}_{2}$ com outros nanomateriais nocivos à saúde humana, que, segundo a literatura, são largamente emitidos pelas indústrias, tais como o óxido de cobre, contaminante de solo onipresente.

Para essa finalidade, foram realizados experimentos em laboratório, utilizando-se os solos do aterro controlado de Volta Redonda-RJ, a fim de se obter informações sobre processos e fenômenos envolvidos na potencial contaminação dos solos, de modo a criar informação científica necessária para melhor compreender o comportamento e o transporte de nanopartículas $\mathrm{TiO}_{2}$ em suspensões aquosas através de solos impregnados com óxido de cobre.

\section{METODOLOGIA}

Essa etapa baseou-se no modelamento físico dos fenômenos envolvidos e teve por objetivo simular, através de experimentos de laboratório, processos e fatores envolvidos em uma possível contaminação de solo com óxido de cobre visando às suas validações. Para isso, foram realizados ensaios de coluna. Os resultados obtidos foram analisados em laboratório particular e comparados com os dados obtidos pelo analisador de partículas Nanosight (NTA 2.3).

\subsection{Ensaio de Coluna}

A relevância na realização do ensaio de coluna reside no fato de que ela simula as condições de fluxo no meio poroso. Com esse ensaio, obtém-se o perfil de concentração do contaminante e seus 
subprodutos ao longo da coluna. 0 ensaio consiste em se percolar a solução do contaminante, através de uma coluna cilíndrica preenchida com solo indeformado. 0 efluente é recolhido periodicamente para determinação da sua concentração.

\subsubsection{O ensaio foi subdividido em dois casos:}

1. Ensaio de percolação com base nos dados empíricos de Fang et al. (2009). Utilizou-se solo puro com a suspensão de $\mathrm{TiO}_{2}(31,530 \mathrm{mg} / \mathrm{L})$, com a adição de água ultrapura (1 litro). A solução percolante resultante foi analisada a cada $75 \mathrm{ml}$ dentre $750 \mathrm{ml}$. As análises ocorreram por ICP-OES e pelo Nanosight, a fim de obtermos informações suficientes para a validação dos resultados obtidos.

2. Esse ensaio consiste na extensão da pesquisa realizada por (Fang, 2009), na qual foram estudados os efeitos das interações das nanopartículas de $\mathrm{TiO}_{2}$ com óxido de cobre. Foram conduzidos em duas modalidades: a primeira modalidade, utilizando-se solo impregnado com óxido de cobre e suspensões aquosas de água ultrapura $(1 \mathrm{~L})$, adicionadas com $\mathrm{TiO}_{2}$ $(31,530 \mathrm{mg} / \mathrm{L})$, somente com água ultrapura. A segunda utilizando-se solo puro (sem contaminação por óxido de cobre) e suspensão de água ultrapura $(1 \mathrm{~L})$, adicionadas com $\mathrm{TiO}_{2}$ $(31,530 \mathrm{mg} / \mathrm{L})$ e $\mathrm{Cu}(20 \mathrm{mg} / \mathrm{L})$.

As soluções foram avaliadas antes e após (concentração final passar pela coluna (concentração inicial). A solução de saída foi centrifugada por $30 \mathrm{~min}$ a $7000 \mathrm{rpm}$, a fim de remover os possíveis resíduos sólidos. Toda solução utilizada neste ensaio foi analisada em laboratório. Para dar início ao ensaio de coluna, foram coletadas amostras de solo de cobertura do aterro controlado de Volta Redonda - RJ/ Brasil. A seguir foram descritos os passos do processo de impregnação do solo com óxido de cobre.

\subsection{Processo de Impregnação do Solo com Óxido de cobre}

A contaminação artificial do solo com óxido de cobre foi conduzida, segundo Di Palma e Ferranteli (2005), com a inoculação de $230 \mathrm{~mL}$ de água ultrapura, contendo 4,16 g de óxido de cobre em $1 \mathrm{~kg}$ de solo previamente seco e peneirado a 1,0 $\mathrm{mm}$. A homogeneização desse material foi realizada por 24 horas, com o auxílio de uma batedeira ajustada a $120 \mathrm{rpm}$. Procurou-se obter um solo com a concentração aproximada de $120 \mathrm{mg} \mathrm{Cu} / \mathrm{kg}$, com as respectivas especificações: dimensão de $30 \mathrm{~nm}$, fornecidas pela Sigma-Aldirich, correspondente a duas vezes o valor de intervenção para um cenário de exposição industrial. Após esse procedimento, o solo foi transferido para um recipiente plástico, no qual permaneceu por 40 dias para secagem ao ar livre.

\subsection{Preparação da Solução}

As soluções de nanopartículas $\mathrm{TiO}_{2}$ foram preparadas, tomando como referencial empírico os dados experimentais de Fang e seus colaboradores (2009). Utilizou-se $\mathrm{TiO}_{2}(2 \mathrm{mg})$ com as respectivas especificações: dimensão de $25 \mathrm{~nm}$ e uma pureza da fase cristalina Anatásio de 99,7\%, fornecidas pela Sigma-Aldrich, com a adição de água ultrapura (1 litro). Em seguida, as respectivas soluções foram distribuídas em frascos de erlenmeyer, mantidas em agitação vigorosa, por 24 horas, com $250 \mathrm{rpm}$ e deixadas em repouso, por dez dias. Após esse período, a solução sobrenadante foi coletada, por meio de uma pipeta, para, então, dar início ao ensaio de coluna. Apenas as soluções que não sofreram decantação, foram utilizadas nos ensaios de coluna. 
Estudo da Interação das Nanopartículas de Dióxido de Titânio em Solos de Aterro Controlado Contaminados por Óxido de Cobre.

\subsection{Montagem da Coluna}

O ensaio de coluna foi realizado em tubos de polietileno de vinila (PVC), com $20 \mathrm{~cm}$ de altura e $5 \mathrm{~cm}$ de diâmetro. A porção inferior do tubo foi equipada com um disco de papel de filtro apoiada em uma malha fina (para evitar a passagem de partículas do solo), conectada a um redutor para facilitar 0 recolhimento do lixiviado. A esquematização da coluna está representada na Figura 1.

Figura 1 - Esquematização da Coluna.

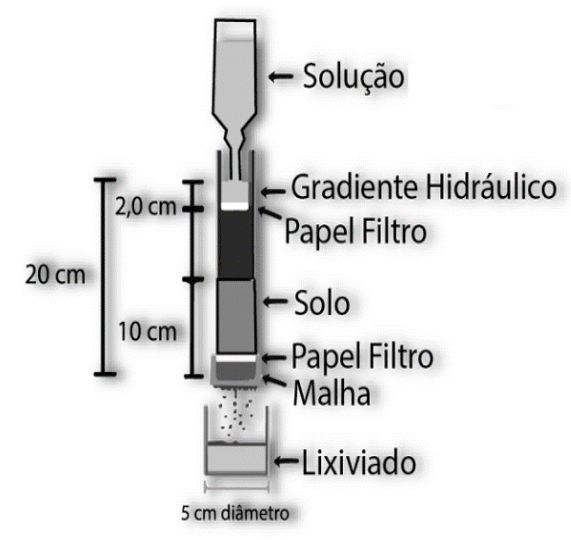

Fonte: dos autores.

Após a construção da coluna, realizou-se o preenchimento manual dos solos em estudo, com $10 \mathrm{~cm}$ de altura da coluna. Em seguida, as colunas de solo foram umedecidas com água ultrapura por ação capilar até a saturação se completar. Os ensaios foram finalizados, após 8 horas do início da percolação. Em seguida, procedeu-se com a centrifugação na solução percolante, quando eles foram mantidos em agitação vigorosa, por 30 minutos, com $7000 \mathrm{rpm}$. 0 centrifugado foi conduzido imediatamente para determinação da concentração de $\mathrm{Cu}$ e $\mathrm{TiO}_{2}$.

\section{RESULTADOS}

Nessa etapa da pesquisa, foram realizadas ensaios de coluna com duração média de 8 horas. Foram coletadas, ao longo do ensaio, 10 amostras de $75 \mathrm{ml}$ da solução percolante, totalizando $750 \mathrm{ml}$, com o objetivo de monitorar a concentração de $\mathrm{TiO}_{2}$ durante a sua estabilização na fase líquida. Para cada 10 amostras coletadas, foi traçado o perfil médio entre as distribuições das concentrações de $\mathrm{TiO}_{2^{\prime}}$ conforme Figura 2. Os dados obtidos também foram analisados por meio de ICP-OES e foram comparados com os resultados empíricos de (Fang, 2009), bem como pelo analisador de partículas, Nanosight. Suas respectivas intensidades relativas foram também avaliadas em cinco amostras coletadas. 
Figura 2 - Perfil Médio de Dióxido de Titânio durante o período de percolação.

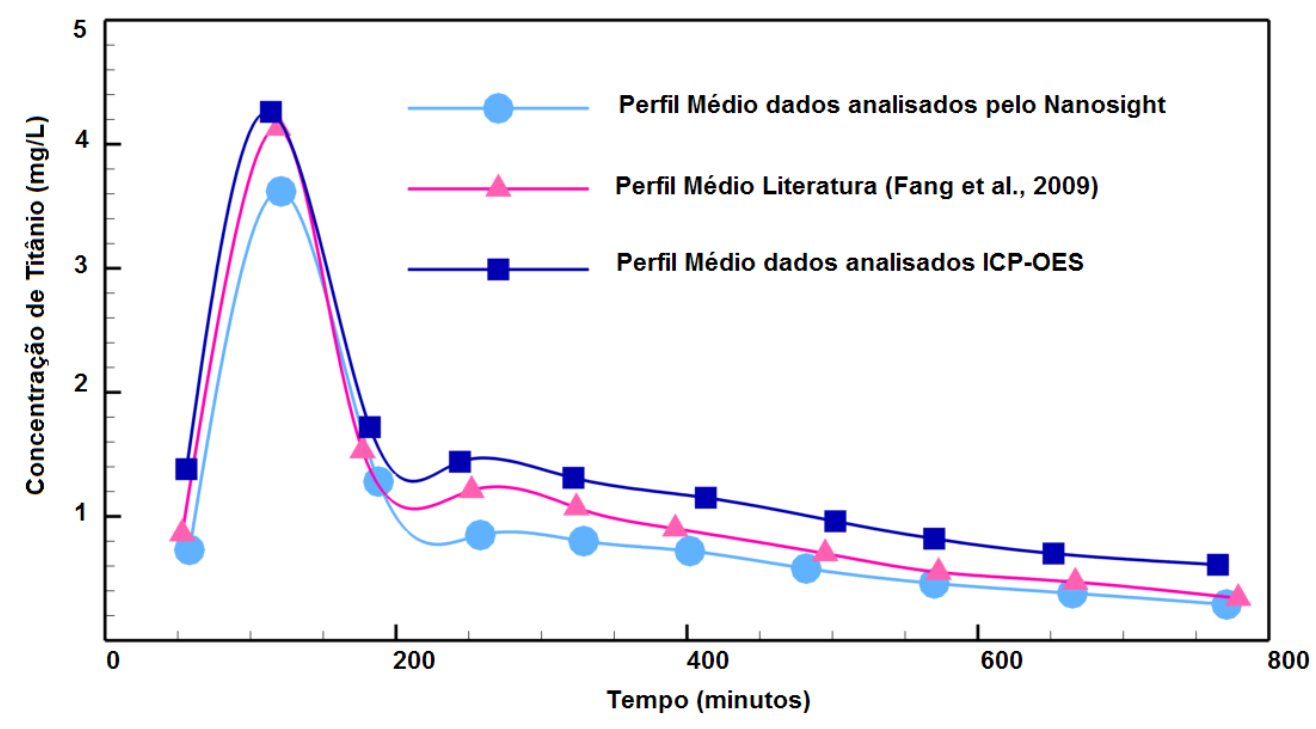

Fonte: dos autores.

A Figura 2 apresenta os respectivos perfis médios das concentração de $\mathrm{TiO}_{2}-\mathrm{NPs}$, ao longo do processo de percolação. Os resultados mostram um pico acentuado da concentração de $\mathrm{TiO}_{2}$, nos primeiros 120 minutos, e, nos minutos subsequentes, o perfil descreve uma queda, resultando numa reduzida concentração de $\mathrm{TiO}_{2}$ na saída da coluna. A Figura 3 corrobora a veracidade dos resultados obtidos no nanosight e mostra que o pico de crescimento permanece de fato nos primeiros 120 minutos do período de percolação, tanto nos dados obtidos da literatura (Fang, 2009) quanto obtidos em laboratório via ICP-OES. 
Figura 3 - Concentração de nanopartículas ao longo da percolação.

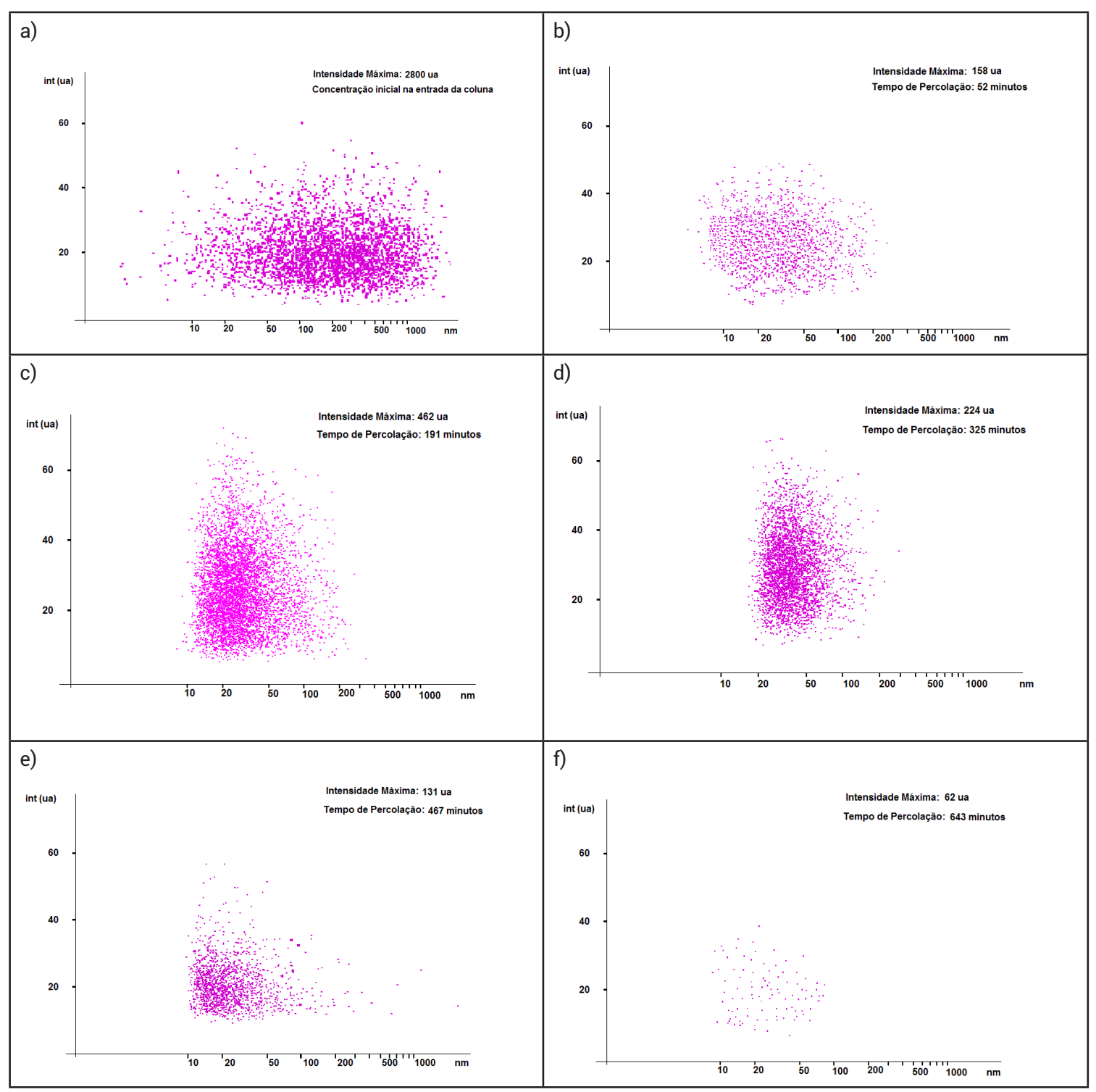

Fonte: dos autores.

Dando continuidade aos experimentos, nessa etapa da pesquisa, foram realizados ensaios com solos contaminados por óxido de cobre, sendo esta a extensão da pesquisa realizada por (FANG, 2009). Com esse ensaio, é possível obter o perfil de concentração do contaminante ao longo da coluna, de modo a investigar a mobilidade de nanopartículas de $\mathrm{TiO}_{2}$ através de solos impregnados com óxido de cobre. Foram utilizados dois tipos de suspensões.

A primeira com água ultrapura e $\mathrm{TiO}_{2}$ e, a segunda solução, apenas com água ultrapura. Ambas as soluções utilizaram o solo impregnado com óxido de cobre. Ao iniciar o processo de percolação, as soluções passaram prontamente pelas colunas de solo, embora a retenção no solo de nanopartículas de $\mathrm{TiO}_{2}$ tenha ocorrido com maior intensidade nesse ensaio, tomando como comparação o ensaio realizado anteriormente. A Tabela 1 mostra a quantidade de $\mathrm{TiO}_{2}$ retido em solos puros e em solos impregnaos com óxido de cobre. 
Tabela 1 - Concentração de $\mathrm{TiO}_{2}$ no lixiviado em solos impregnados com CuO.

\begin{tabular}{|c|c|c|}
\hline \multicolumn{3}{|c|}{ Suspensão Aquosa (Água ultrapura e TiO2) } \\
\hline Concentração de TiO2 (mg/L) & Solo Puro & Solo Impregnado com CuO \\
\hline Entrada & \multicolumn{2}{|l|}{$31,53 \mathrm{mg} / \mathrm{L}$} \\
\hline Saída & 0,79 & 0,03 \\
\hline Presente Inicialmente no Solo & \multicolumn{2}{|c|}{$965,82 \mathrm{mg} / \mathrm{L}$} \\
\hline Retido no Solo após Percolação & 996,56 & 997,32 \\
\hline \multicolumn{3}{|c|}{ Suspensão Aquosa (Água ultrapura) } \\
\hline Concentração de TiO2 (mg/L) & Solo Puro & Solo Impregnado com CuO \\
\hline Saída & 0,01 & 0,01 \\
\hline Presente Inicialmente no Solo & \multicolumn{2}{|c|}{$965,82 \mathrm{mg} / \mathrm{L}$} \\
\hline Retido no Solo após Percolação & 965,81 & 965,82 \\
\hline
\end{tabular}

Observa-se, que em ambos os ensaios, sejam com a solução de água ultrapura e $\mathrm{TiO}_{2}$ ou somente com água ultrapura, a concentração de $\mathrm{TiO}_{2}$ sorvido pelo solo é mais acentuada, quando se utiliza solos impregnados com óxido de cobre. Desse modo, o óxido de cobre teve um papel crucial para a contribuição na agregação e a deposição de nanopartículas de $\mathrm{TiO}_{2}$.

\section{CONCLUSÕES}

Foram observados que, nos ensaios em que o tempo médio de percolação foi maior, tem-se um número menor de nanopartículas de $\mathrm{TiO}_{2}$, proveniente de uma menor velocidade de percolação e, consequentemente, um maior tempo de contato entre as partículas sólidas do solo com as nanopartículas de $\mathrm{TiO}_{2}$. Então, pode-se concluir que, quanto maior for a variação de tempo de percolação, menor será sua concentração final no lixiviado, que, por sua vez, apresentará maior concentração de nanopartículas no solo. Na segunda etapa dos ensaios, objetivou-se compreender o comportamento e o transporte de nanopartículas $\mathrm{TiO}_{2}$ em suspensões aquosas através de solos impregnados com óxido de cobre. Os resultados obtidos mostraram um aumento significativo de $0,1 \%$ na concentração de $\mathrm{TiO}_{2}$ no solo, em ambas as suspensões com solos impregnados com óxido de cobre, o que nos leva a concluir a influência do óxido de cobre no processo de deposição de nanopartículas de $\mathrm{TiO}_{2}$ em solos. 
Estudo da Interação das Nanopartículas de Dióxido de Titânio em Solos de Aterro Controlado Contaminados por Óxido de Cobre.

\section{REFERÊNCIAS}

FANG, J., SHAN, X. Q., WEN, B., LIN, J. M., OWENS, G. Stability of Titania Nanoparticles in Soil Suspensions and Transport in Saturated Homogeneous Soil Columns. Environmental Pollution, v.4, p.1101-1109, 2009.

HEIDEN, T.C.K., DENGLER, E., KAO, W. J., HEIDEMAN, W., PETERSON, R.E. Developmental Toxicity of Low Generation Pamam Dendrimers in Zebrafish. Toxicology and Applied Pharmacology, v. 225, p. 70-79, 2008.

HANDY, R.D., VON DER KAMMER, F., LEAD, J.R., HASSELLO“V, M., OWEN, R., CRANE, M. The ecotoxicology and chemistry of manufactured nanoparticles. Ecotoxicology, v.17, p.287-314, 2008.

KLAINE, S.J., P.J.J., ALVAREZ, G.E., BATLEY, T.F., Fernandes, R.D., HANDY, D.Y., LYON, S., MAHENDRA, M.J., MCLAUGHLIN and J.R., LEAD. Nanomaterials in the environment: Behavior, Fate, Bioavailability and Effects. Environment Toxicology Chemical, v. 27, p.1825-1851, 2008.

OLIVEIRA, E. M., CASTRO, J. A., LEAO, I. Study of the Interaction of Copper Nanoparticles with Titanium in Landfill Soils Layers. Materials Science Forum, v. 869, p. 778-783, 2016.

OLIVEIRA, E. M., NOGUEIRA, D. A., LOPES, L. C. R., FEITEIRA, J. F. S., CASTRO, J. A., Analysis of Percolation of the Stabilized Suspensions of $\mathrm{TiO}_{2}$ and $\mathrm{SiO}_{2}$ Nanoparticles in Soil Columns Simulating Landfill Layers. Journal of Mechanics Engineering and Automation, v. 6, p. 47-52, 2016.

OLIVEIRA, E. M., VALADÃO, I. C. R. P., ARAÚJO, A. S. F., CASTRO, J. A. Application of Nanoparticle Tracking Analysis (NTA) in Aqueous Solutions of $\mathrm{TiO}_{2}$. Materials Science Forum, v. 802, p. 624-629, 2014.

WANG H., WICK R.L., XING B. Toxicity of nanoparticulate and bulk $\mathrm{ZnO}, \mathrm{Al}_{2} \mathrm{O}_{3}$ and $\mathrm{TiO}_{2}$ to the nematode Caenorhabditis elegans. Environmental Pollution, v. 157, p. 1171-1177, 2009.

WIESNER, M.R., LOWRY, G.V., ALVAREZ, P., DIONYSIOU, D., BISWAS, P. Assessing the risks of manufactured nanomaterials. Environmental Science \&Technology, v. 40, p. 4336-4345, 2006.

WITTMER, C.R., PHELPS, J.A., LEPUS, C.M., SALTZMAN, W.M., HARDING, M.J., VAN TASSEL, P.R. Multilayer nanofilms as substrates for hepatocellular applications. Biomaterials, v. 29, p. 4082-4090, 2008.

ZHANG, L., WEBSTER, T.J., 2009. Nanotechnology and nanomaterials:promises for improved tissue regeneration. Nano Today, v.4, p. 66-80, 2009. 